\title{
COST OF INSURANCE: A NOTE ON PUT VALUATION UNDER A CONSTRAINT
}

\author{
José Antonio Núñez Mora* \\ Departamento de Contabilidad y Finanzas \\ Tecnológico de Monterrey, Campus Ciudad de México \\ (Received 23 August 2005, accepted 30 September 2005)
}

\begin{abstract}
In the arrangement of a loan, a governmental guarantee of deposits can be made to banks. The issuing of the guarantee creates a cost on the guarantor. Evaluation of this cost has been made with the option pricing theory (Merton (1977)). In this paper, we have added a more specific partition of liabilities of the bank and a constraint. The partition and constrain permit us deduce a possible modification of the cost of insurance using the same option pricing theory, based on the Karatzas and Shreve (1998) and Karatzas and Kou (1996).
\end{abstract}

\section{Resumen}

En el acuerdo de un préstamo puede existir la garantía gubernamental para los bancos. El que exista una garantía crea un costo para el asegurado. La elevación de este costo se ha llevado a cabo con la teoría de valuación de opciones (Merton (1977)). En este artículo hemos agregado una partición más específica de los pasivos del banco y una restricción. La existencia de la partición y la restricción nos permite deducir una posible modificación del costo de aseguramiento. Esto se hace en Karatzas y Shreve (1998) y Karatzas y Kou (1996).

JEL classification: Go, N2

Keywords: Cost of Insurance, Rectangular Constraint, Support Function

Tecnológico de Monterrey, Campus Ciudad de México, Departamento de Contabilidad y Finanzas, Calle del Puente 222, Oficinas 3, Segundo Piso, Col. Ejidos de Huipulco, Deleg. Tlalpan, c.p. 14380. México, D. F. Telephone: +52(55)5483 2240. E-mail: janm@itesm.mx 


\section{Introduction}

The cost of insurance has been identified with a valuation of a put option in Merton (1997). In that paper, we find a stochastic differential equation with a single Brownian motion and a direct application of the option pricing theory. However, the portfolio of the bank, can be subdivided into different quality asset. Moreover, the investments of the bank could find constraints of several types. One of these constraints, called rectangular is illustrated in this paper. An adaptation of the model of Karatzas and Kou (1996) has been developed for the case of the deposit valuation. In section 2, we show the essentials of the theory and in section 3, the adaptation to the bank and insurance theory. Section 4 , gives conclusions.

\section{Essentials of the Theory}

As an easy way to understand the concepts, we can check the two periods case as it is shown in Rochet and Freixas (1997). At $t=0$ the bank pays the premium of deposit insurance. In the period $t=1$, the depositors are compensated if the bank assets are lesser than the liabilities. We can see this in Table 1.

Table 1.

\begin{tabular}{|c|c|c|c|c|c|c|c|}
\hline assets & & liabilities & & assets & & liabilities & \\
\hline Loans & $L$ & Deposits & $D$ & $\begin{array}{c}\text { Loan } \\
\text { Repayments }\end{array}$ & $\tilde{L}$ & Deposits & $D$ \\
\hline $\begin{array}{c}\text { Insurance } \\
\text { Premium }\end{array}$ & $P$ & Equity & $F$ & $\begin{array}{c}\text { Insurance } \\
\text { Payment }\end{array}$ & $\tilde{S}$ & $\begin{array}{c}\text { Liquidation } \\
\text { Value }\end{array}$ & $\tilde{V}$ \\
\hline & $t=0$ & & & & $t=1$ & & \\
\hline
\end{tabular}

The payment from the deposit insurance is:

$$
\tilde{S}=\max \{0, D-\tilde{L}\}
$$

which can be seen as a put option on the assets bank $\tilde{L}$ with strike price $D$, (Merton (1977)). In that paper, the value of the banks assets follows a geometric random walk

$$
\mathrm{d} \tilde{L} / \tilde{L}=\mu \mathrm{d} t+\sigma \mathrm{d} W
$$

where $W$ is a Brownian motion. The no arbitrage price of the deposit insurance in then calculated with the known put formula of Black and Scholes.

Now suppose that the total value of the assets is divided into parts $\tilde{L}_{0}, \tilde{L}_{1}$ $, \cdots, \tilde{L}_{d}$, which are of different quality and they are correlated, i.e.,

$$
\begin{gathered}
\mathrm{d} \tilde{L}_{0}(t)=\tilde{L}_{0}(t) r(t) \mathrm{d} t, \quad \tilde{L}_{0}(0)=1 \\
\mathrm{~d} \tilde{L}_{i}(t)=\tilde{L}_{i}(t)\left[b_{i}(t) \mathrm{d} t+\sum_{j=1}^{d} \sigma_{i j}(t) \mathrm{d} W_{j}(t)\right], \quad \tilde{L}_{i}(0)=l_{i}, \quad i=1,2, \cdots, d .
\end{gathered}
$$


We will call $\tilde{L}_{i}$ the money lending in the $i t h$ loan. Under this specification note that

$$
\tilde{L}_{i}(t)=l_{i} \exp \left\{\left(b_{i}-\frac{1}{2} \sum_{j=1}^{d} \sigma_{i j}^{2}\right) t+\sum_{j=1}^{d} \sigma_{i j} W_{j}(t)\right\}
$$

(see Karatzas and Shreve (1988)). So the movement of the value of each project through time is influenced by the noise of the other projects.

Here $W(t)=\left(W_{1}(t), \cdots, W_{d}(t)\right)^{*}$ is a standard brownian motion in $R^{d}$. This entries represent independent sources of uncertainty. In this model, we have a rate of growth (deterministic) in the level of $\tilde{L}_{i}(t)$, and the coefficient $\sigma_{i j}(t)$ is the influence (intensity) of the $j t h$ source of uncertainty on the ith asset.

The Brownian motion $W$ is defined on a complete probability space $(\Omega, F$, $P)$. The completation of the natural filtration $F_{t}^{W}=\sigma(W(s) ; 0 \leq s \leq t)$ will be denoted by $\left\{F_{t}\right\}$. It is assumed that the vector $b(t)=\left(b_{1}(t), b_{2}(t), \cdots, b_{d}(t)\right)^{*}$ and the matrix $\sigma(t)=\left\{\sigma_{i j}(t)\right\}_{1 \leq i, j \leq d}$, are progressively measurable with respect to $\left\{F_{t}\right\}$ and uniformly bounded in $(t, w) \in[0, T] \times \Omega$. Moreover, a condition of nondegeneracy on the matrix $a(t)=\sigma(t) \sigma^{\prime}(t)$ is necessary, related with the existence of a solution of (3) (Karatzas and Kou (1996)):

$$
\xi^{\prime} a(t) \xi \geq \varepsilon\|\xi\|^{2}, \quad \forall(t, \xi) \in[0, T] \times R^{d} .
$$

Without loss of generality we can suppose that the bond free of risk is $\tilde{L}_{0}$. If the total value of the assets is $\tilde{L}$, then

$$
\tilde{L}=\tilde{L}_{0}+\tilde{L}_{1}+\cdots+\tilde{L}_{d}
$$

and we introduce the constants

$$
\lambda_{i}=\frac{\tilde{L}_{i}}{\tilde{L}}, \quad i=0,1,2, \cdots d
$$

For each $\tilde{L}_{i}$ we have a respective put option, which can be written as

$$
\tilde{S}_{i}=\max \left\{0, D_{i}-\tilde{L}_{i}\right\}, \quad i=0,1, \cdots, d,
$$

where $D=D_{0}+D_{1}+\cdots+D_{d}$.

Here, for $i=0,1, \cdots, d, D_{i}=f\left(\tilde{L}_{i}\right)$ is a function of each $\tilde{L}_{i}$. As an easy example take $D_{i}=\lambda_{i} D$. We know that

$$
\lambda_{i} \tilde{S}_{i}=\max \left\{0, \lambda_{i} D-\lambda_{i} \tilde{L}\right\}
$$

So

$\sum_{i=0}^{d} \lambda_{i} \tilde{S}_{i}=\sum_{i=0}^{d} \lambda_{i} \max \{0, D-\tilde{L}\}=\max \{0, D-\tilde{L}\} \sum_{i=0}^{d} \lambda_{i}=\max \{0, D-\tilde{L}\}=\tilde{S}$ 
In general, we will suppose that $D_{i}=\gamma_{i} D$, where $\sum_{i=0}^{d} \gamma_{i}=1$ and each $\gamma_{i}$ is not necessarily equal to $\lambda_{i}$.

\section{The Model}

Now supposed that the bank is limited about the amount of money invested on the ith project. The key point is the constraint. In the context of stock options (Karatzas and Kou (1996), Karatzas and Shreve (1998)), the equivalent situation are the called rectangular constraints (Cvitanic and Karatzas (1993)).

The stochastic differential equation driven by the system (Karatzas and Kou (1996)) is

$$
\begin{aligned}
& \mathrm{d} X(t)=X(t)\left[1-\sum_{i=1}^{d} \pi_{i}(t)\right] \frac{\mathrm{d} P_{0}(t)}{P_{0}(t)}+\sum_{i=1}^{d} X(t) \pi_{i}(t) \frac{\mathrm{d} P_{i}(t)}{P_{i}(t)} \\
& =X(t)\left[1-\sum_{i=1}^{d} \pi_{i}(t)\right] r(t) \mathrm{d} t+\sum_{i=1}^{d} X(t) \pi_{i}(t) b_{i}(t) \mathrm{d} t+\sum_{j=1}^{d} \sigma_{i j}(t) \mathrm{d} W_{j}(t) \\
& =X(t) r(t) \mathrm{d} t+X(t) \pi_{t}^{\prime} \sigma(t) \mathrm{d} W_{0}(t), \quad X(0)=x>0
\end{aligned}
$$

where $\pi_{i}$ is the proportion of the total amount of money $X(t)$ invested in the ith project.

In the case of rectangular constraints (see Karatzas and Shreve (1998), Rockafellar (1970)): $K=I_{1} \times I_{2} \times \cdots \times I_{N}$, where $I_{N}=\left[\alpha_{n}, \beta_{n}\right]$ and $-\infty \leq$ $\alpha_{n} \leq 0 \leq \beta_{n} \leq \infty$. It can be seen that the effective domain is $R^{n}$. In this case the support function is

$$
\delta(x)=\sum_{i=1}^{d} \beta_{i} x_{i}^{-}-\sum_{i=1}^{d} \alpha_{i} x_{i}^{+}
$$

where $x^{-}=\max \{-x, 0\}$ denotes the negative part of the real number $x$, and $x^{+}=\max \{x, 0\}$ is the positive part.

In the general case (Cvitanic and Karatzas (1992)), the effective domain is

$$
\begin{gathered}
\tilde{K}=\left\{x \in R^{d} ; x_{i} \geq 0, \forall_{i} \in \eta_{+}, \text {and }, x_{j} \leq 0, \forall_{j} \in \eta_{-}\right\} \\
\eta_{+}=\left\{i=1,2, \cdots, d \mid \beta_{i}=\infty\right\} \\
\eta_{-}=\left\{i=1,2, \cdots, d \mid \alpha_{j}=-\infty\right\}
\end{gathered}
$$

For the case of the European put option where the underlying asset is driven by a single Brownian motion (denoting the volatility $\sigma_{11}$ by $\sigma$ ) we have several cases (Karatzas and Shreve (1998) and equations (3),(4),(5)):

(i) If $\alpha=-\infty$ (the interval is open on the left) then $\gamma(x)=(x-D)^{+}$,

(ii)If $\alpha=0$, then $\gamma(x)=D$, 
(iii) If $-\infty<\alpha<0$,

$$
\gamma(x)= \begin{cases}D-x, & 0<x \leq \frac{\alpha D}{\alpha-1} \\ \left(\frac{|\alpha-1|}{D}\right)^{\alpha-1}\left(\frac{x}{|\alpha|}\right)^{\alpha}, & x \geq \frac{\alpha D}{\alpha-1} .\end{cases}
$$

The value of the put is given by $P^{*}=e^{-r T} \mathrm{E}_{0}\left[\gamma\left(\tilde{L}_{i}(0) \exp \{\sigma W(T)+(r-\right.\right.$ $\left.\left.\sigma^{2} / 2\right) T\right\}$. As in Merton (1977), we can see that the option valuation is reduced to the non constrained case when $\alpha=-\infty$.

\section{Conclusions}

The existence of constraints in the portfolio of a bank originates a variety of possible prices for the deposit of insurance. These prices are correct because they are free of arbitrage (see Karatzas and Kou (1996)). For the practitioners is necessary to know about these kind of results because the money lended in different quality loans is an important information.

\section{References}

Freixas, X. and J. C. Rochet (1997). Microeconomics of Banking, Massachusetts Institute of Technology.

Cvitanic, J. and I. Karatzas (1992). Convex Duality in Constrained Portfolio Optimization. Annals of Applied Probability, 2, pp. 767-818.

Cvitanic, J. and I. Karatzas (1993). Hedging Contingent Claims with Constrained Portfolios. Annals of Applied Probability, 3, pp. 652-681.

Karatzas, I. and S. Kou (1996). On the Pricing of Contingent Claims under Constraints. Annals of Applied Probability, 6, pp. 321-369.

Karatzas, I. and S. Shreve (1998). Brownian Motion and Stochastic Calculus. Springer, Berlin-Heidelberg-New York.

Karatzas, I. and S. Shreve (1998). Methods of Mathematical Finance. Springer, BerlinHeidelberg-New York.

Rockafellar, R. (1970). Convex Analysis. Princeton University Press, Princeton NJ. 